\title{
Synthesis and X-ray Crystal Structures of Cobalt and Copper Complexes of 1,3-Bis(benzotriazolyl)propanes.
}

\author{
Philip Børsting ${ }^{\mathrm{a}}$ and Peter J. Steel ${ }^{\mathrm{b} *}$ \\ ${ }^{a}$ Department of Chemistry, University of Southern Denmark, Campusvej 55, 5230 Odense M, \\ Denmark. \\ ${ }^{b}$ Department of Chemistry, University of Canterbury, Christchurch, New Zealand.
}

\begin{abstract}
Two propylene-bridged bis-benzotriazole ligands, $\mathbf{1}$ and 2, were used to obtain three novel coordination polymers with cobalt(II), copper(II) and copper(I). The complexes were structurally characterised by X-ray crystallography. The complex $\left[\mathrm{Co}(\mathbf{1}) \mathrm{Cl}_{2}\right]_{\mathrm{n}}, 3$, possesses a helical zig-zag chain structure in which tetrahedral $\mathrm{CoCl}_{2}$ centres are bridged by molecules of $\mathbf{1}$ having an extended conformation. The complex $\left[\mathrm{Cu}(\mathbf{1}) \mathrm{Cl}_{2}\right]_{\mathrm{n}}, \mathbf{4}$, exhibits a more complex supramolecular architecture, which extends in two dimensions with bridging through $\mathrm{Cu}_{2} \mathrm{Cl}_{4}$ dimeric units in one direction and through the organic ligand in an orthogonal direction. The complex $[\mathrm{Cu}(2) \mathrm{Cl}]_{\mathrm{n}}, \mathbf{6}$, has a one-dimensional polymeric structure involving 16-membered $\mathrm{M}_{2} \mathrm{~L}_{2}$ rings bridged by $\mathrm{Cu}_{2} \mathrm{Cl}_{2}$ units.
\end{abstract}

Keywords: Copper complexes / Cobalt complexes / Benzotriazole / Bridging ligands / N ligands

\footnotetext{
* Corresponding author. Tel.: +64-3-3642432; fax: +64-3-3642110;

e-mail:p.steel@chem.canterbury.ac.nz.
} 


\section{Introduction}

The use of linear and angular components for the controlled self-assembly of two- and threedimensional metallosupramolecular species has been the subject of considerable study in recent years. ${ }^{[1]}$ The most commonly employed organic connecting components are rigid linear bridging heterocyclic ligands, such as pyrazine and 4,4'-bipyridine. More recently, flexible ligands have been employed in order to gain access to topologies not available from logical combination of rigid building blocks. The simplest way to introduce flexibility into ligand design is by the incorporation of alkyl chain spacer groups. For example, symmetrical ligands containing propylene spacer groups between 4-pyridyl- ${ }^{[2]} 8$-quinolyloxy-,${ }^{[3]} 1$-pyrazolyl-,${ }^{[4]} 1$-triazolyl- ${ }^{[5]}$ and 2-benzimidazolyl- ${ }^{[6]}$ donor groups have recently been used for the construction of interesting new supramolecular architectures.

For some years now we have been involved in the synthesis and study of ligands containing less commonly studied heterocyclic ring systems. ${ }^{[7]}$ One such heterocycle is benzotriazole, which is extensively used as a synthetic auxiliary in organic chemistry ${ }^{[8]}$ but has been largely ignored by coordination chemists. The parent heterocycle can coordinate up to three metals in its deprotonated form, ${ }^{[9]}$ with particular emphasis having been placed on copper complexes, due to the importance of benzotriazole as a corrosion inhibitor. ${ }^{[10]}$ We have recently reported the incorporation of benzotriazole groups into a number of chelating ligands ${ }^{[1]]}$ and into a bidentate bridging ligand which forms a triple stranded helicate. ${ }^{[12]}$ We now describe complexes of two symmetrical isomeric ligands, $\mathbf{1}$ and $\mathbf{2}$, which contain benzotriazole groups separated by flexible propylene spacer units (Figure 1).

((Figure 1 here)) 


\section{Results and Discussion}

The ligands 1 and 2 were prepared by reaction of benzotriazole with 1,3-dibromopropane in the presence of sodium hydroxide in DMSO solution, as previously described by Katritzky et al. ${ }^{[13]}$ This reaction produces a mixture of the symmetrical 1,1'- and 2,2'-isomers, $\mathbf{1}$ and $\mathbf{2}$, along with the unsymmetrical $1,2^{\prime}$-isomer. The three isomers were separated by column chromatography on silica gel and recrystallized from absolute ethanol and their properties were in accord with those described previously. ${ }^{[13]}$ However, ligand $\mathbf{1}$ has recently been described by other workers ${ }^{[14]}$ who reported a ${ }^{1} \mathrm{H}$ NMR spectrum which we believe to be that of isomer 2 . In order to resolve this discrepancy unambiguously, we carried out an X-ray crystal structure determination of the compound we identified as 2 .

Figure 2 shows a perspective view of the structure of this ligand, which is indeed the 2,2'isomer, in agreement with the NMR assignment of Katritzky et al. ${ }^{[13]}$ The compound crystallizes in the orthorhombic space group $\mathrm{P} 2{ }_{1} 2_{1} 2_{1}$ with a complete molecule in the asymmetric unit. The bonding geometry of the benzotriazole rings is similar to that in other 2-alkylbenzotriazoles. ${ }^{[13,15]} \mathrm{In}$ the solid state it adopts an unsymmetrical conformation about the central propylene spacer group. Specifically, one of the benzotriazole rings exists in a gauche conformation [N2'-C1-C2-C3 torsional angle $\left.=59.0(2)^{\circ}\right]$, while the other has the expected anti conformation [C1-C2-C3-N2" torsional angle $\left.=172.2(1)^{\circ}\right]$. This unusual shape undoubtedly results from a complex system of intermolecular forces, comprising face-to-face and edge-to-face aromatic interactions ${ }^{[16]}$ as well as $\mathrm{C}-\mathrm{H}^{\cdots \cdots} \mathrm{N}$ interactions, ${ }^{[17]}$ all of which are now well known to contribute significantly to the solid state structures of heteroaromatic compounds.

((Figure 2 here))

Having unambiguously established the structures of the ligands, we proceeded to study their coordination chemistry. All three ligands were reacted with a variety of first row transition metal salts. Complexes of the unsymmetrical 1,2'-isomer failed to assemble into any crystalline product. However, reactions of $\mathbf{1}$ and $\mathbf{2}$ with both cobalt(II) chloride and copper(II) chloride furnished single crystals suitable for X-ray structure determination.

Reaction of cobalt(II) chloride with $\mathbf{1}$ formed $\left[\mathrm{Co}(\mathbf{1}) \mathrm{Cl}_{2}\right]_{\mathrm{n}}, 3$, which is a one-dimensional coordination polymer. Figure 3 shows a perspective view of a section of the extended structure with selected atom labelling. The complex crystallizes in the orthorhombic space group Pnna, with half the ligand and half a $\mathrm{CoCl}_{2}$ in the asymmetric unit. Thus, the distorted tetrahedral cobalt atom and the central carbon of the propylene group (C2) each lie on different two-fold rotation axes. The resulting polymer chains extend into a helical zig-zag pattern in which the bridging ligand adopts the most extended possible form, with anti conformations of the propylene spacer [N1-C1-C2-C1B torsional angle $\left.=179.6(2)^{\circ}\right]$ and coordination by the less sterically hindered $\mathrm{N} 3$ nitrogens, as was observed for the $\mathrm{CuCl}_{2}$ complex of the related ligand with a methylene spacer group. ${ }^{[1]}$ As a result 
the ligand bridges cobalt atoms separated by $12.462(1) \AA$. The polymer chains stack on each other by face to face interactions between the benzotriazole groups in a way such that each chain stacks with four other chains.

\section{((Figure 3 here $)$ )}

Analogous reaction of $\mathbf{1}$ with copper(II) chloride led to a complex $\left[\mathrm{Cu}(\mathbf{1}) \mathrm{Cl}_{2}\right]_{\mathrm{n}}, \mathbf{4}$, with a more complex supramolecular architecture. It crystallizes in the monoclinic space group $\mathrm{P} 2{ }_{1} / \mathrm{n}$ with a dichlorocopper(II) unit and a whole bridging ligand in the asymmetric unit. Figure 4 shows a perspective view of the contents of the asymmetric unit and the symmetry related connecting atoms. The benzotriazole rings are both coordinated through the N3 nitrogens in preference to the more sterically congested N2 nitrogens. Within the complex 4 the bridging ligand exists in a more compact conformation than was observed in 3 . In particular the propylene bridge folds into a gauche-gauche conformation [N1"-C1-C2-C3 torsional angle $=57.2(3)^{\circ}$ and $\mathrm{C} 1-\mathrm{C} 2-\mathrm{C} 3-\mathrm{N} 1$ ' torsional angle $=68.0(3)^{\circ}$ ], which is similar to that observed in a zinc(II) thiocyanate complex of the same ligand. ${ }^{[14]}$ As a consequence, copper atoms bridged by the ligand $\mathbf{1}$ are separated by only 9.157(1) A, much less than the metal-metal separation in 3.

\section{((Figure 4 here $))$}

The copper atom is five-coordinate, being bonded to two molecules of $\mathbf{1}$, that are related by a crystallographic glide plane, a terminal chlorine atom and two bridging chlorines that are related by a centre of inversion. The geometry of the copper is square pyramidal with a tau value ${ }^{[18]}$ of 0.088 and with one of the bridging chlorines occupying the axial site. The terminal chlorine has a bond length of 2.283(1) $\AA$ and the two bridging chlorines have bond lengths of 2.324(1) and 2.644(1) $\AA$, which gives the $\mathrm{Cu}_{2} \mathrm{Cl}_{2}$ unit a parallelogram-like shape, which by virtue of the crystallographic centre of inversion is strictly planar. The $\mathrm{Cu} 1{ }^{\cdots} \mathrm{Cu}$ 1 A interatomic distance across the parallelogram is 3.509(1) $\AA$. These distances are within the range of other known di- $\mu$-chlorocopper(II) complexes. $^{[7,10 b, 19]}$

The bridging nature of the heterocyclic ligand serves to extend the structure in one dimension. Further bridging by the chlorines results in orthogonal extension of the structure so as to produce a complicated two-dimensional network. Within this network there exists large 44-membered fused metallocyclic ring systems as $\mathrm{M}_{6} \mathrm{~L}_{4}$ units, one of which is shown in Figure 5. A stabilising influence within this structure appears to come from $\pi-\pi$ stacking between benzotriazole rings separated by the $\mathrm{Cu}_{2} \mathrm{Cl}_{2}$ units. These rings lie perpendicular to the $\mathrm{Cu}_{2} \mathrm{Cl}_{2}$ plane, and are separated by approximately $3.5 \AA$, although they are offset such that the centroids of the benzo rings are separated by ca. $4.18 \AA$.

\section{((Figure 5 here))}

Reaction of 2 with cobalt(II) chloride gave a $\left[\mathrm{Co}(2) \mathrm{Cl}_{2}\right]_{\mathrm{n}}$ complex, 5, as a light blue solid, which failed to produce any crystals suitable for X-ray crystallography. In contrast, reaction of 2 
with copper(II) chloride in methanol gave, quite unexpectedly, a copper(I) species as lemon coloured crystals. This surprising result proved to be quite reproducible, although the identity of the metal reductant remains undetermined. The resulting polymeric $[\mathrm{Cu}(2) \mathrm{Cl}]_{\mathrm{n}}$ complex 6 crystallizes in the monoclinic space group $\mathrm{C} 2 / \mathrm{c}$, with a copper(I) chloride unit and a whole bridging ligand in the asymmetric unit. Figure 6 shows a perspective view of the contents of the asymmetric unit and the symmetry related connecting atoms.

\section{((Figure 6 here $))$}

Within the complex the ligand adopts a conformation quite similar to that found in the structure of the free ligand 2 , with one benzotriazole group adopting a gauche conformation to the propylene linker $\left[\mathrm{C} 1-\mathrm{C} 2-\mathrm{C} 3-\mathrm{N} 2 "\right.$ torsional angle $\left.=64.9(4)^{\circ}\right]$ and the other an anti conformation $\left[\mathrm{N} 2\right.$ '-C1-C2-C3 torsional angle $\left.=177.8(3)^{\circ}\right]$. This results in a relatively short intermetallic separation across the ligand bridge $[\mathrm{Cu} 1 \cdots \mathrm{Cu} 1 \mathrm{~B}=6.010(1) \AA]$. The copper(I) atom has tetrahedral geometry with coordination to two bridging chlorine atoms, related by a two-fold rotation axis, and two nitrogens of different ligands related by a centre of inversion. The $\mathrm{Cu}-\mathrm{Cl}$ bond distances are relatively symmetric [2.372(1) and 2.429(1) $\AA$ ] and are in the range of other known binuclear $\mathrm{Cu}_{2} \mathrm{Cl}_{2}$ complexes. ${ }^{[20]}$ The $\mathrm{Cu}_{2} \mathrm{Cl}_{2}$ unit is non-planar with a rather short $\mathrm{Cu}{ }^{\cdots} \mathrm{Cu}$ contact $[\mathrm{Cu} 1 \cdots \mathrm{Cu} 1 \mathrm{~A}$ $=2.8093(8) \AA]$. The $\mathrm{Cu}-\mathrm{N} 1$ distances are also within the range of similar known binuclear $\mathrm{Cu}_{2} \mathrm{Cl}_{2}$ complexes. ${ }^{[20]}$ Two molecules of ligand 2 bridge two copper atoms, thereby generating a 16membered $\mathrm{M}_{2} \mathrm{~L}_{2}$ ring structure about a crystallographic centre of inversion. As shown in Figure 7 these rings further extend into a one-dimensional polymeric structure through the chloro bridges. Once again, the extended structure appears to be stabilised by $\pi-\pi$ stacking interactions across the $\mathrm{Cu}_{2} \mathrm{Cl}_{2}$ units between adjacent benzotriazole systems, whose mean-planes are separated by ca. 3.5 $\AA$.

((Figure 7 here))

\section{Conclusion}

The present study has shown that benzotriazole is a useful heterocyclic ring system for incorporation into bridging ligands. The bidentate ligands $\mathbf{1}$ and $\mathbf{2}$, having flexible propylene linkers, generate one- and two-dimensional coordination polymeric networks with copper and cobalt chlorides.

\section{Experimental}

\section{General Procedures and Ligand Syntheses}

NMR spectra were recorded on a Varian Unity 300 spectrometer with a $3 \mathrm{~mm}$ probe and operating at $300 \mathrm{MHz}$ and $75 \mathrm{MHz}$ for ${ }^{1} \mathrm{H}$ and ${ }^{13} \mathrm{C}$, respectively. Melting points were determined 
using an Electrothermal melting point apparatus and are uncorrected. Elemental analyses were performed by the Campbell Microanalytical laboratory at the University of Otago.

The ligands were prepared according to the procedure of Katritzky et al. ${ }^{[13]}$ This gave a mixture of 1 [m.p. $139-139.5^{\circ} \mathrm{C}$ (lit. $\left.{ }^{[13]} 119-121^{\circ} \mathrm{C}\right)$ ], 2 [119-121 ${ }^{\circ} \mathrm{C}\left(\right.$ lit. $\left.\left.^{[13]} 116-118^{\circ} \mathrm{C}\right)\right]$ and the unsymmetrical $1,2^{\prime}$-disubstituted isomer $\left[80-81^{\circ} \mathrm{C}\left(\right.\right.$ lit. $\left.\left.^{[13]} 83-83.5^{\circ} \mathrm{C}\right)\right]$, which were separated by chromatography on silica gel and recrystallized from ethanol.

\section{Preparation of Complexes}

Cobalt(II) chloride complex of 1, viz 3.

1,3-Bis(benzotriazol-1-yl)propane (10 mg, $0.036 \mathrm{mmol}$ ) was dissolved in boiling $\mathrm{MeOH}$ (1 $\mathrm{mL})$ and added to a solution of $\mathrm{CoCl}_{2} \cdot 6 \mathrm{H}_{2} \mathrm{O}(8.5 \mathrm{mg}, 0.036 \mathrm{mmol})$ in $\mathrm{MeOH}(1 \mathrm{~mL})$. After 20 days blue plate crystals suitable for X-ray crystallography had formed. The crystals were removed and washed with $\mathrm{MeOH}$. Yield: $8.5 \mathrm{mg}, 58 \%$, m.p. $=322^{\circ} \mathrm{C}$. Anal. Calcd for $\mathrm{C}_{15} \mathrm{H}_{14} \mathrm{~N}_{6} \mathrm{CoCl}_{2}$ (408.15): C: 44.14; H: 3.46; N: 20.59\%. Found: C: 44.28; H: 3.27; N: 20.48\%.

Copper(II) chloride complex of $\mathbf{1}$, viz 4.

$\mathrm{CuCl}_{2} \cdot 2 \mathrm{H}_{2} \mathrm{O}(6.0 \mathrm{mg}, 0.035 \mathrm{mmol})$ was dissolved in $\mathrm{MeOH}(3 \mathrm{~mL})$ and added to a solution of 1,3-bis(benzotriazol-1-yl)propane (10 mg, $0.036 \mathrm{mmol})$ dissolved in hot $\mathrm{MeOH}(3 \mathrm{~mL})$. The light green mixture was mixed well and left standing at room temperature. After a few minutes blue crystals began to form and after 1 hour the solution was colourless. The blue block shaped crystals was stable in air and suitable for X-ray diffraction. Yield: $11.9 \mathrm{mg}, 82 \%$, m.p. $=274^{\circ} \mathrm{C}$. Anal. Calcd for $\mathrm{C}_{15} \mathrm{H}_{14} \mathrm{~N}_{6} \mathrm{CuCl}_{2}$ (412.76): C: 43.65; H: 3.42; N: 20.36\%. Found: C: 43.76; H: 3.37; N: 20.15\%.

Cobalt(II) chloride complex of 2 , viz 5.

1,3-Bis(benzotriazol-2-yl)propane $(32.4 \mathrm{mg}, 0.116 \mathrm{mmol})$ and $\mathrm{CoCl}_{2} \cdot 6 \mathrm{H}_{2} \mathrm{O}(25.2 \mathrm{mg}, 0.106$ mmol) was stirred and refluxed in $\mathrm{MeOH}(8 \mathrm{~mL})$ for $16 \mathrm{~h}$, which resulted in a blue solution. The blue solution was evaporated in vacuo and redissolved in $\mathrm{CHCl}_{3}(2 \mathrm{~mL})$ and subjected to slow evaporation, which gave a light blue solid. Yield: $39 \mathrm{mg}, 90 \%$, m.p. $=265-266^{\circ} \mathrm{C}$. Anal. Calcd for $\mathrm{C}_{15} \mathrm{H}_{14} \mathrm{~N}_{6} \mathrm{CoCl}_{2}$ (408.15): C: 44.14; H: 3.46; N: 20.59\%. Found: C: 43.89; H: 4.07; N: 20.29\%.

Copper(I) chloride complex of 2, viz 6.

1,3-Bis(benzotriazol-2-yl)propane (10 mg, $0.036 \mathrm{mmol}$ ) was dissolved in boiling $\mathrm{MeOH}$ (1 $\mathrm{mL})$ and $\mathrm{CuCl}_{2} \cdot 2 \mathrm{H}_{2} \mathrm{O}(6.0 \mathrm{mg}, 0.036 \mathrm{mmol})$ dissolved in $\mathrm{MeOH}(1 \mathrm{~mL})$ was added. The pale green solution was mixed well. After a few days lemon coloured crystals suitable for X-ray crystallography had formed. The crystals were filtered off and washed with MeOH. Yield: $4.9 \mathrm{mg}$, $36 \%$, m.p. $=199^{\circ} \mathrm{C}$. Anal. Calcd for $\mathrm{C}_{15} \mathrm{H}_{14} \mathrm{~N}_{6} \mathrm{CuCl}$ (377.31): C: 47.64; H: 3.73; N: 22.22\%. Found: C: 47.69; H: 3.58; N: 22.06.

\section{X-Ray Crystallography}


Crystal data and experimental details of the data collections and structure refinements are listed in Table 1. Data were collected with a Siemens SMART CCD area detector, using graphite monochromatised Mo K $\alpha$ radiation $(\lambda=0.71073 \AA)$. Almost complete spheres of data were collected. The structures were solved by direct methods using SHELXS, ${ }^{[21]}$ and refined on $\mathrm{F}^{2}$ using all data by full-matrix least-squares procedures with SHELXL-97. ${ }^{[22]}$ Hydrogen atoms were included in calculated positions with isotropic displacement parameters 1.3 times the isotropic equivalent of their carrier atoms. The function minimised was $\Sigma \mathrm{w}\left(\mathrm{F}_{\mathrm{o}}{ }^{2}-\mathrm{F}_{\mathrm{c}}{ }^{2}\right)^{2}$, with $\mathrm{w}=\left[\sigma^{2}\left(\mathrm{~F}_{\mathrm{o}}^{2}\right)+\right.$ $\left.(\mathrm{aP})^{2}+\mathrm{bP}\right]^{-1}$, where $\mathrm{P}=\left[\max \left(\mathrm{F}_{\mathrm{o}}, 0\right)^{2}+2 \mathrm{~F}_{\mathrm{c}}^{2}\right] / 3$. CCDC numbers 207061-207064 contain the supplementary crystallographic data for this paper. These data can be obtained free of charge at www.ccdc.cam.ac.uk/conts/retrieving.html [or from the Cambridge Crystallographic Data Centre, 12 Union Road, Cambridge CB2 1EZ, UK; fax: (internat.) + 44-1223/336-033; Email: deposit@ccdc.cam.ac.uk].

((Table 1 here)) 


\section{References}

[1] For recent reviews, see: ${ }^{[1 \mathrm{a}]}$ S. Leininger, B. Olenyuk, P. J. Stang, Chem. Rev., 2000, 100, 853908. ${ }^{[1 \mathrm{~b}]}$ G. F. Swiegers, T. J. Malefetse, Chem. Rev., 2000, 100, 3483-3538. ${ }^{[1 \mathrm{c}]}$ B. Moulton, M. J. Zaworotko, Chem. Rev., 2001, 101, 1629-1658. ${ }^{[1 \mathrm{~d}]}$ M. Fujita, K. Umemoto, M. Yoshizawa, N. Fujita, T. Kusukawa, K. Biradha, Chem. Commun., 2001, 509-518. ${ }^{[1 \mathrm{e}]}$ D. W. Johnson, K. N. Raymond, Supramol. Chem., 2001, 13, 639-659. ${ }^{[1 \mathrm{f}]}$ B. J. Holliday, C. A. Mirkin, Angew. Chem. Int. Ed., 2001, 40, 2022-2043. ${ }^{[\mathrm{g}]}$ G. F. Swiegers, T. J. Malefetse, Coord. Chem. Rev., 2002, 225, 91-121.

[2] For recent examples, see: ${ }^{[2 a]}$ M. J. Plater, M. R. S. J. Foreman, T. Gelbrich, S. J. Coles, M. B. Hursthouse, J. Chem. Soc., Dalton Trans., 2000, 3065-3073. ${ }^{[2 \mathrm{~b}]}$ F. M. Tabellion, S. R. Seidel, A. M. Arif, P. J. Stang, Angew. Chem. Int. Ed., 2001, 40, 1529-1532. ${ }^{[2 \mathrm{c}]}$ F. M. Tabellion, S. R. Seidel, A. M. Arif, P. J. Stang, J. Am. Chem. Soc., 2001, 123, 11982-11990. ${ }^{[2 \mathrm{~d}]}$ M. J. Plater, M. R. S. J. Foreman, T. Gelbrich, M. B. Hursthouse, Inorg. Chim. Acta, 2001, 318, 171-174. ${ }^{[2 \mathrm{e}]}$ L. Pan, E. B. Woodlock, X. Wang, K.-C. Lam, A. L. Rheingold, Chem. Commun., 2001, 1762-1763. ${ }^{[2 f]}$ L. Carlucci, G. Ciani, M. Moret, D. M. Proserpio, S. Rizzato, Chem. Mater., 2002, 14, 12-16. ${ }^{[2 \mathrm{~g}]}$ W. J. Belcher, C. A. Longstaff, M. R. Neckenig, J. W. Steed, Chem. Commun., 2002, 1602-1603. ${ }^{[2 \mathrm{~h}]}$ E.-Q. Gao, Z.-W. Wang, C.-S. Liao, C.-H. Yan, New J. Chem., 2002, 26, 1096-1098. ${ }^{[2 \mathrm{i}]}$ M. T. Bujaci, X. Wang, S. Li, C. Zheng, Inorg. Chim. Acta, 2002, 333, 152-154.

[3] M. R. A. Al-Mandhary, P. J. Steel, Aust. J. Chem., 2002, 55, 705-708.

[4] ${ }^{[4 a]}$ A. M. Schuitema, M. Engelen, I. A. Koval, S. Gorter, W. L. Driessen, J. Reedijk, Inorg. Chim. Acta, 2001, 324, 57- 64. ${ }^{[4 b]}$ D. A. McMorran, S. Pfadenhauer, P. J. Steel, Aust. J. Chem., 2002, 55, 519-522.

[5] ${ }^{[5 a]}$ G. A. Van Albada, R. C. Guijt, J. G. Haasnoot, M. Lutz, A. L. Spek, J. Reedijk, Eur. J. Inorg. Chem., 2000, 121-126. ${ }^{[5 b]}$ Q. Zhao, H. Li, X. Wang, Z. Chen, New J. Chem., 2002, 26, 1709-1710.

[6] ${ }^{[6 a]}$ G. A. van Albada, M. T. Lakin, N. Veldman, A. L. Spek, J. Reedijk, Inorg. Chem., 1995, 34, 4910-17. ${ }^{[6 b]}$ G. A. van Albada, W. J. J. Smeets, A. L. Spek, J. Reedijk, Inorg. Chim. Acta, 2000, 299, 35-40. ${ }^{[6 c]}$ I. Riggio, G. A. van Albada, D. D. Ellis, I. Mutikainen, A. L. Spek, U. Turpeinen, J. Reedijk, Polyhedron, 2001, 20, 2659-2666.

[7] C. Richardson, P. J. Steel, Eur. J. Inorg. Chem., 2003, 405-408, and references therein.

[8] A. R. Katritzky, X. Lan, J. Z. Yang, O. V. Denisko, Chem. Rev., 1998, 98, 409-548.

[9] ${ }^{[9 a]}$ D. S. Moore, S. D. Robinson, Adv. Inorg. Chem., 1988, 32, 171-239, and references therein. ${ }^{[9 b]}$ M. Murrie, D. Collison, C. D. Garner, M. Helliwell, P. A. Tasker, S. S. Turner, Polyhedron, 1998, 17, 3031-3043. 
[10] ${ }^{[10 \mathrm{a}]}$ R. Walker, J. Chem. Educ., 1980, 57, 789-791. ${ }^{[10 \mathrm{~b}]}$ I. Soetofte, K. Nielsen, Acta Chem. Scand., 1981, A35, 733-738. ${ }^{[10 c]}$ H. M. J. Hendriks, J. J. M. W. L. Birker, G. C. Verschoor, J. Reedijk, J. Chem. Soc., Dalton Trans., 1982, 623-631. ${ }^{[10 \mathrm{~d}]}$ G. F. Kokoszka, J. Baranowski, C. Goldstein, J. Orsini, A. D. Mighell, V. L. Himes, A. R. Siedle, J. Am. Chem. Soc., 1983, 105, 5627-5633. ${ }^{[10 e]}$ J. Reedijk, A. R. Siedle, R. A. Velapoldi, J. A. M. Van Hest, Inorg. Chim. Acta, 1983, 74, 109-118.

[11] C. Richardson, P. J. Steel, Dalton Trans., 2003, 992-1000.

[12] B. J. O'Keefe, P. J. Steel, Inorg. Chem. Commun., 2000, 3, 473-475.

[13] A. R. Katritzky, A. Jesorka, J. Wang, B. Yang, J. Wu, P. J. Steel, Liebigs Ann., 1996, 745-755.

[14] X. Meng, Y. Song, H. Hou, Y. Fan, G. Li, Y. Zhu, Inorg. Chem., 2003, 42, 1306-1318.

[15] ${ }^{[15 a]}$ A. R. Katritzky, J. Wu, W. Kuzmierkiewicz, S. Rachwal, M. Balasubramanian, P. J. Steel, Liebigs Ann. Chem., 1994, 7-12. ${ }^{[15 b]}$ A. R. Katritzky, P. J. Steel, S. N. Denisenko, Tetrahedron, 2001, 57, 3309-3314.

[16] ${ }^{[16 a]}$ C. A. Hunter, K. R. Lawson, J. Perkins, C. J. Urch, J. Chem. Soc., Perkin Trans. 2, 2001, 651-669. ${ }^{[16 b]}$ W. B. Jennings, B. M. Farrell, J. F. Malone, Acc. Chem. Res., 2001, 34, 885894. ${ }^{[16 c]}$ E. A. Meyer, R. K. Castellano, F. Diederich, Angew. Chem. Int. Ed., 2003, 42, 12101250.

[17] J. J. M. Amoore, L. R. Hanton, M. D. Spicer, Dalton Trans., 2003, 1056-1058, and references therein.

[18] A. W. Addison, T. Nageswara Rao, J. Reedijk, J. van Rijn, G. C. Verschoor, J. Chem. Soc., Dalton Trans., 1984, 1349-1356.

[19] ${ }^{[17 a]}$ P. C. Christidis, C. A. Bolos, G. S. Nikolov, Inorg. Chim. Acta, 1995, 237, 123-130. ${ }^{[17 b]}$ M. Melnik, M. Kabesova, M. Koman, L. Macaskova, J. Garaj, C. E. Holloway, A. Valent, J. Coord. Chem., 1998, 45, 147-359.

$[20]{ }^{[18 a]}$ O. M. Yaghi, G. Li, Angew. Chem., Int. Ed. Engl., 1995, 34, 207-209. ${ }^{[18 b]}$ Y. C. M. Pennings, W. L. Driessen, J. Reedijk, Polyhedron, 1988, 7, 2583-2589.

[21] G. M. Sheldrick, Acta Crystallogr., Sect. A, 1990, 46, 467-473.

[22] G. M. Sheldrick, SHELXL-97, University of Göttingen, 1997. 


\section{Figure Captions}

Figure 1. Structures of ligands 1 and 2.

Figure 2. Perspective view of the X-ray crystal structure of ligand 2.

Figure 3. Perspective view, with selected atom labelling, of the one-dimensional coordination polymer $\left[\mathrm{Co}(\mathbf{1}) \mathrm{Cl}_{2}\right]_{\mathrm{n}}, 3$. Selected bond lengths $(\AA)$ and angles $\left({ }^{\circ}\right)$ : Co1-N3 2.011(2); Co-Cl1 2.2235(6); N3-Co1-N3A 108.2(1); N3-Co1 Cl1 104.33(5); N3-Co1-Cl1A 112.02(5).

Figure 4. Perspective view showing the contents of the asymmetric unit and connected atoms (dashed bonds), with selected atom labelling, in the crystal structure of $\left[\mathrm{Cu}(\mathbf{1}) \mathrm{Cl}_{2}\right]_{\mathrm{n}}, \mathbf{4}$. Selected bond lengths ( $\AA$ ) and angles $\left({ }^{\circ}\right)$ : Cu1-N3' 2.014(2); Cu1-N3"A 2.026(2); Cu1-C11 2.2834(8); Cu1Cl2 2.6442(8); Cu1-C12A 2.3238(8); N3'-Cu1-N3"A 166.56(8); N3'-Cu1-Cl1 88.57(6); N3"ACu1-Cl1 90.75(6); N3'-Cu1-Cl2A 87.95(6); N3"A-Cu1-Cl2A 90.21(6); Cl1-Cu1-Cl2A 168.94(3); N3'-Cu1-Cl2 96.83(6); N3"A-Cu1-Cl2 96.49(6); Cl1-Cu1-Cl2 100.47(3); Cl2A-Cu1-Cl2 90.36(2); $\mathrm{Cu} 1-\mathrm{Cl} 2-\mathrm{Cu} 1 \mathrm{~A}$ 89.64(2).

Figure 5. Perspective view of a section of the extended two-dimensional polymeric structure of 4 .

Figure 6. Perspective view showing the contents of the asymmetric unit and connected atoms (dashed bonds), with selected atom labelling, in the crystal structure of $[\mathrm{Cu}(2) \mathrm{Cl}]_{\mathrm{n}}, 6$. Selected bond lengths $(\AA)$ and angles $\left({ }^{\circ}\right)$ : Cu1-N1' 2.011(3); Cu1-N1”A 2.015(3); Cu1-Cl1 2.3724(9); Cu1-Cl1A 2.4287(9); N1'-Cu1-N1"A 115.3(1); N1'-Cu1-Cl1 112.29(8); N1"A-Cu1-Cl1 111.19(8); N1'-Cu1C11A 108.30(8); N1"A-Cu1-C11A 107.59(8); C11-Cu1-Cl1A 101.01(3).

Figure 7. Perspective view of a section of the extended one-dimensional polymeric structure of 6. 
Table 1. X-ray crystal data and details of data collections and structure refinements.

\begin{tabular}{|c|c|c|c|c|}
\hline Compound & 2 & 3 & 4 & 6 \\
\hline Formula & $\mathrm{C}_{15} \mathrm{H}_{14} \mathrm{~N}_{6}$ & $\mathrm{C}_{15} \mathrm{H}_{14} \mathrm{~N}_{6} \mathrm{CoCl}_{2}$ & $\mathrm{C}_{15} \mathrm{H}_{14} \mathrm{~N}_{6} \mathrm{CuCl}_{2}$ & $\mathrm{C}_{15} \mathrm{H}_{14} \mathrm{~N}_{6} \mathrm{CuCl}$ \\
\hline Formula Weight & 278.32 & 408.15 & 412.76 & 377.31 \\
\hline Crystal System & orthorhombic & orthorhombic & monoclinic & monoclinic \\
\hline$a(\AA)$ & $5.8393(6)$ & $14.377(2)$ & $9.692(2)$ & 11.693(1) \\
\hline$b(\AA)$ & $5.9826(6)$ & $13.997(2)$ & $15.309(3)$ & $17.876(1)$ \\
\hline$c(\AA)$ & $38.695(4)$ & $8.037(1)$ & $11.093(2)$ & $15.444(1)$ \\
\hline$\beta\left(^{\circ}\right)$ & 90 & 90 & $91.312(2)$ & $112.131(1)$ \\
\hline $\mathrm{V}\left(\AA^{3}\right)$ & 1351.8 & $1617.2(3)$ & $1645.5(5)$ & $2990.5(4)$ \\
\hline Space Group & $\mathrm{P} 2{ }_{1} 2_{1} 2_{1}$ & Pnna & $\mathrm{P} 2_{1} / \mathrm{n}$ & $\mathrm{C} 2 / \mathrm{c}$ \\
\hline $\mathrm{Z}$ & 4 & 4 & 4 & 8 \\
\hline $\mathrm{D}_{\mathrm{C}}\left(\mathrm{Mg} \mathrm{m}^{-3}\right)$ & 1.368 & 1.676 & 1.666 & 1.647 \\
\hline $\mathrm{F}(000)$ & 584 & 828 & 836 & 1536 \\
\hline Temperature $(\mathrm{K})$ & $168(2)$ & $165(2)$ & $295(2)$ & $165(2)$ \\
\hline Crystal Form & colourless block & blue plate & blue block & lemon block \\
\hline Crystal Size (mm) & $0.61 \times 0.57 \times 0.24$ & $0.40 \times 0.39 \times 0.03$ & $0.34 \times 0.14 \times 0.14$ & $0.65 \times 0.14 \times 0.11$ \\
\hline$\mu\left(\mathrm{mm}^{-1}\right)$ & 0.088 & 1.401 & 1.661 & 1.647 \\
\hline $2 \theta \max \left({ }^{\circ}\right)$ & 52.78 & 53.12 & 52.80 & 50.00 \\
\hline Unique reflections & 2752 & 1680 & 3297 & 2638 \\
\hline Completeness (\%) & 99.5 & 99.0 & 97.6 & 99.8 \\
\hline Parameters & 190 & 110 & 217 & 208 \\
\hline $\mathrm{R}^{\mathrm{a}}[\mathrm{I}>2 \sigma(\mathrm{I})]$ & 0.0351 & 0.0304 & 0.0298 & 0.0421 \\
\hline $\mathrm{wR}^{\mathrm{b}}$ (all data) & 0.0832 & 0.0776 & 0.0846 & 0.1050 \\
\hline
\end{tabular}

a $R=\Sigma\left(\left|F_{O}\right|-\left|F_{C}\right|\right) / \Sigma\left|F_{O}\right| . \quad b_{w R}=\left(\Sigma\left[w\left(F_{O}^{2}-F_{C}^{2}\right)^{2}\right] / \Sigma\left[w\left(F_{O}^{2}\right)^{2}\right]\right)^{1 / 2}$. 
Figure 1. Structures of ligands 1 and 2.

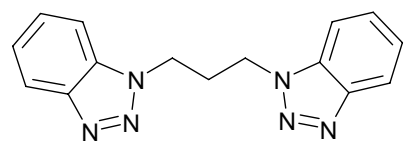

(1)

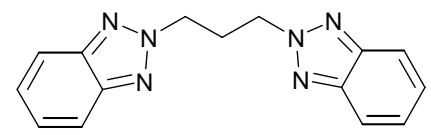

(2) 
Figure 2. Perspective view of the X-ray crystal structure of ligand 2.

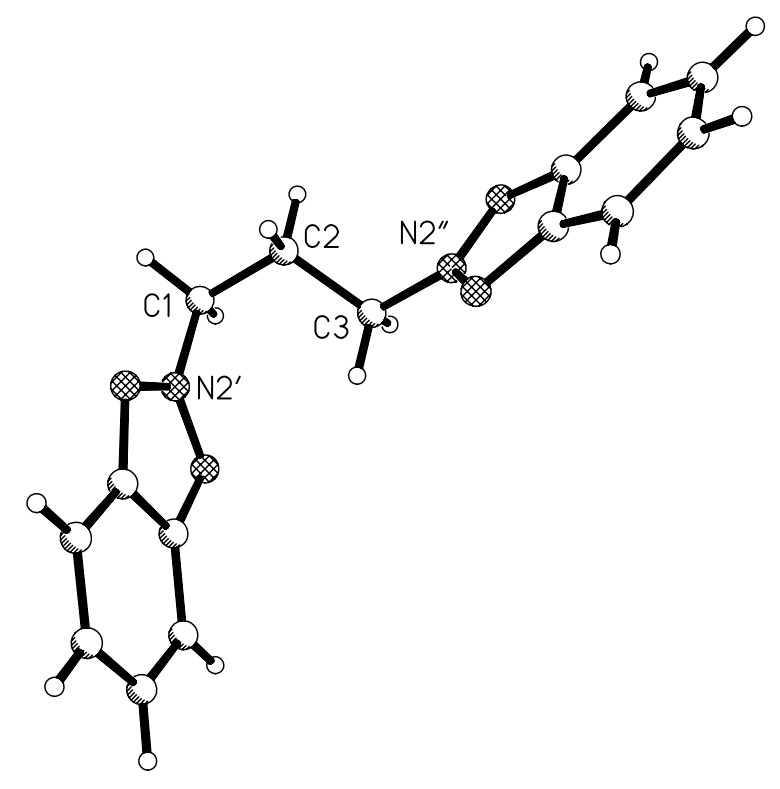


Figure 3. Perspective view, with selected atom labelling, of the one-dimensional coordination polymer $\left[\mathrm{Co}(\mathbf{1}) \mathrm{Cl}_{2}\right]_{\mathrm{n}}, 3$. Selected bond lengths $(\AA)$ and angles $\left({ }^{\circ}\right)$ : Co1-N3 2.011(2); Co-C11 2.2235(6); N3-Co1-N3A 108.2(1); N3-Co1 Cl1 104.33(5); N3-Co1-Cl1A 112.02(5); Cl1-Co1-Cl1A 115.94(4).

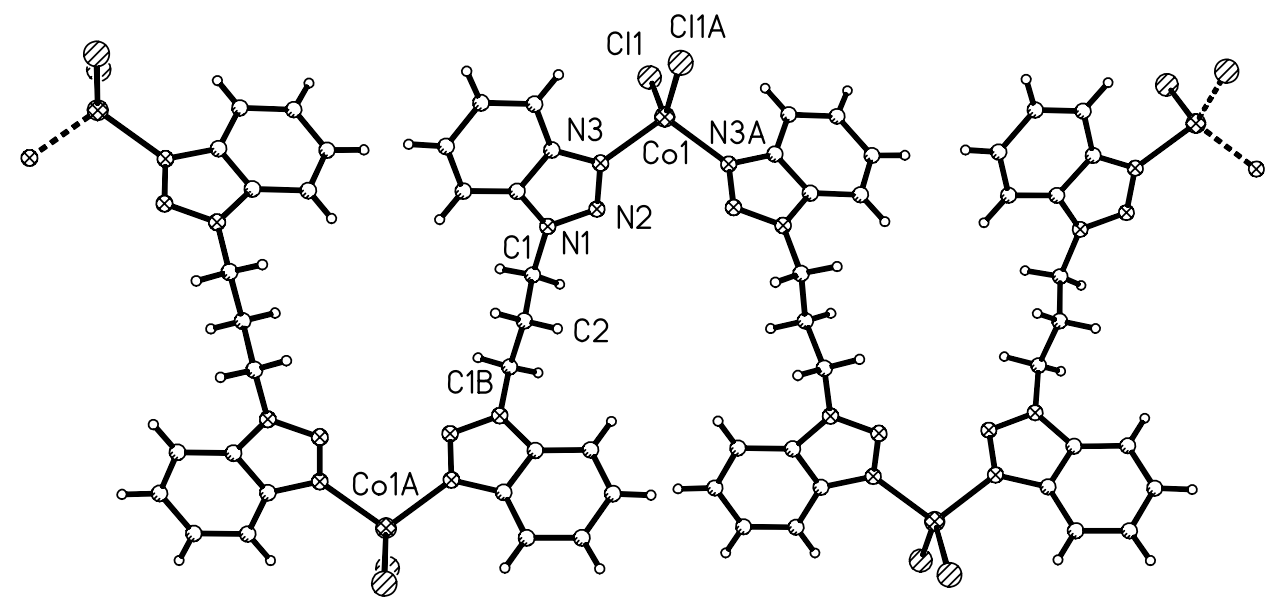


Figure 4. Perspective view showing the contents of the asymmetric unit and connected atoms (dashed bonds), with selected atom labelling, in the crystal structure of of $\left[\mathrm{Cu}(\mathbf{1}) \mathrm{Cl}_{2}\right]_{\mathrm{n}}$, 4. Selected bond lengths $(\AA)$ and angles $\left({ }^{\circ}\right)$ : Cu1-N3' 2.014(2); Cu1-N3"A 2.026(2); Cu1-Cl1 2.2834(8); Cu1Cl2 2.6442(8); Cu1-Cl2A 2.3238(8); N3'-Cu1-N3"A 166.56(8); N3'-Cu1-Cl1 88.57(6); N3"ACu1-Cl1 90.75(6); N3'-Cu1-Cl2A 87.95(6); N3"A-Cu1-Cl2A 90.21(6); Cl1-Cu1-Cl2A 168.94(3); N3'-Cu1-Cl2 96.83(6); N3"A-Cu1-Cl2 96.49(6); Cl1-Cu1-Cl2 100.47(3); Cl2A-Cu1-Cl2 90.36(2); $\mathrm{Cu} 1-\mathrm{Cl} 2-\mathrm{Cu} 1 \mathrm{~A}$ 89.64(2).

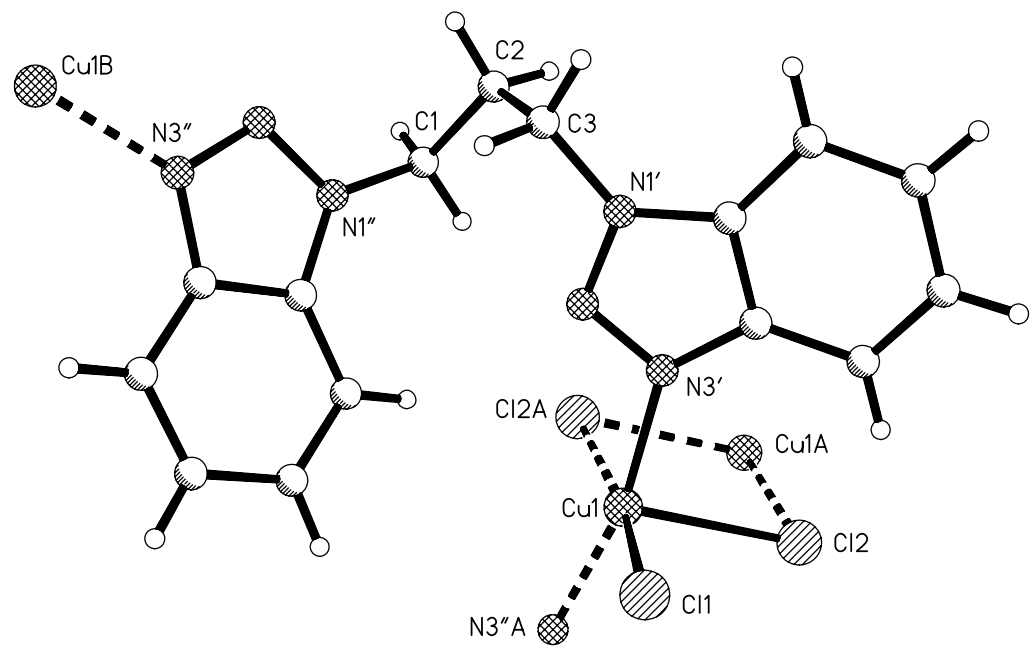


Figure 5. Perspective view of a section of the extended two-dimensional polymeric structure of 4 .

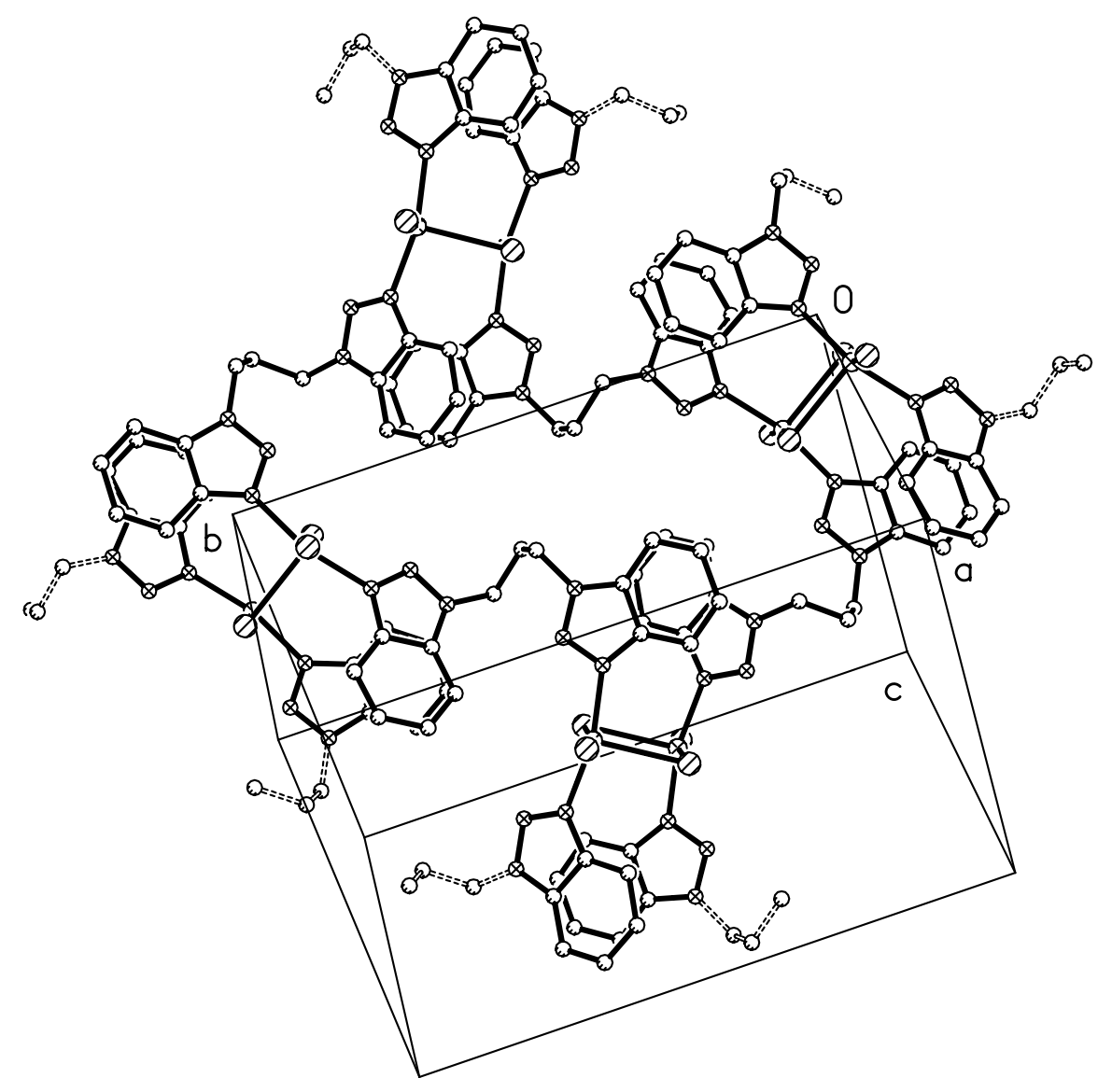


Figure 6. Perspective view showing the contents of the asymmetric unit and connected atoms (dashed bonds), with selected atom labelling, in the crystal structure of $[\mathrm{Cu}(2) \mathrm{Cl}]_{\mathrm{n}}, 6$. Selected bond lengths $(\AA)$ and angles $\left({ }^{\circ}\right)$ : Cu1-N1' 2.011(3); Cu1-N1”A 2.015(3); Cu1-Cl1 2.3724(9); Cu1-Cl1A 2.4287(9); N1'-Cu1-N1"A 115.3(1); N1'-Cu1-Cl1 112.29(8); N1"A-Cu1-Cl1 111.19(8); N1'-Cu1Cl1A 108.30(8); N1"A-Cu1-Cl1A 107.59(8); Cl1-Cu1-Cl1A 101.01(3).

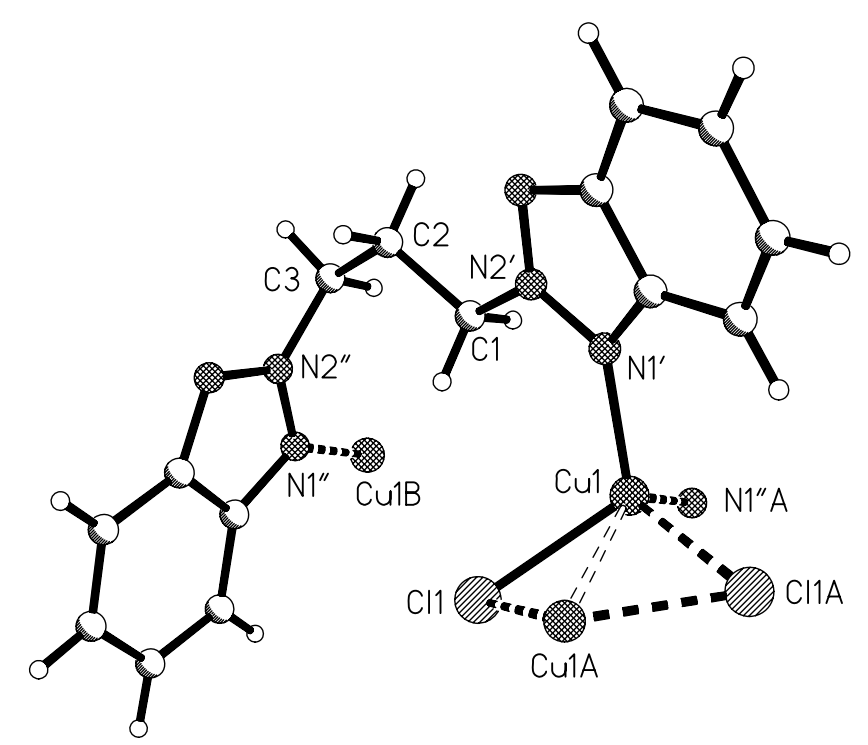


18

Figure 7. Perspective view of a section of the extended one-dimensional polymeric structure of 6 .

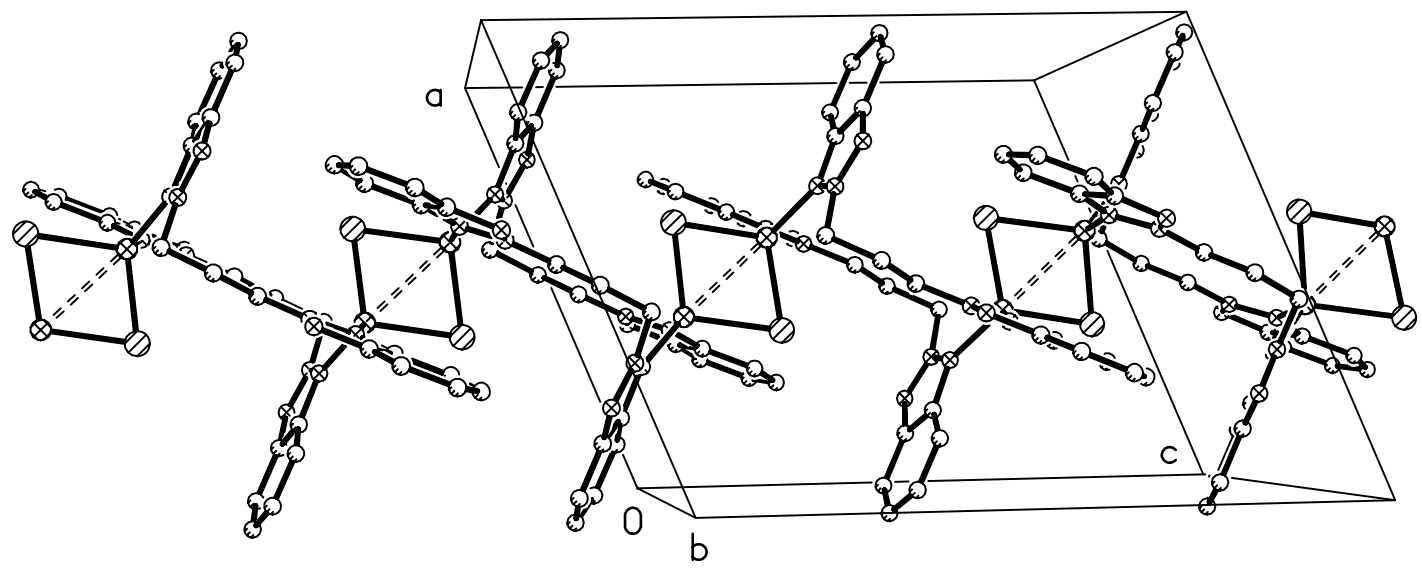




\section{Graphical Abstract}

\section{Philip Børsting and Peter J. Steel*}

Synthesis and X-ray Crystal Structures of Cobalt and Copper Complexes of 1,3Bis(benzotriazolyl)propanes.

Keywords: Copper complexes; Cobalt complexes; Benzotriazole; Bridging ligands; N ligands.
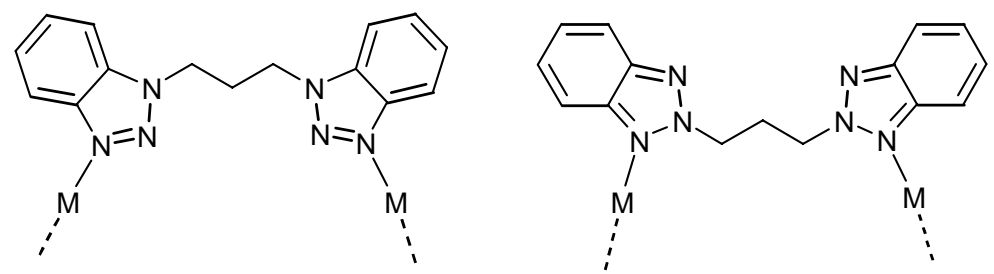